\title{
Research on IPO Pricing Mechanism Based on Auction
}

\author{
Yunzhao Lu \\ Fuzhou University of International Studies and Trade \\ Fuzhou, China 350200
}

\begin{abstract}
There are three pricing methods: fixed price, auction and accumulative bid pricing. Although cumulative bidding pricing is the first choice of major capital markets in the world, in recent years, Some financial markets in some countries and regions have started to adopt auction methods again and have perfected various auction mechanisms in the process of IPO pricing and become the pricing mechanism approved by the market. Based on the current situation of China A-share IPO market, this paper puts forward an auction model to analyze the role of this model in the pricing of new shares, and concludes that with the increase of the number of small and medium-sized investors, this paper makes a certain sort of research on the pricing mechanism of new shares. Institutional investors will be allocated less shares and information rentals, while issuers' earnings will increase.
\end{abstract}

Keywords-IPO; medium and small investors; mechanism design; information asymmetry

\section{INTRODUCTION}

The first open issue (IPO) is an important part of the financial market, and even to some extent it can be seen as a barometer of the volatility of the whole financial market and the overall economy. IPO pricing mechanism mainly includes three pricing methods: fixed price, auction and cumulative bid pricing. At present, the evolution of global IPO pricing mechanism as a whole has emerged the following trends: fixed prices and auction pricing methods are more and more not used by many countries or regions; The accumulative bidding pricing has gradually become the primary choice of the major capital markets in the world, and gradually occupies the dominant position. In recent years, the American cumulative bidding, which includes the characteristics of road-show, bookkeeping and tilting to institutional investors and patrons, has been adopted by most countries and regions. Although the market in many countries and regions no longer adopts auction and instead adopts the method of cumulative bidding, in recent years, some financial markets in some countries and regions have started to adopt auction methods again, and in the new issue pricing process to improve the various auction mechanisms, and then become the most recognized by the market issue pricing mechanism.

There is no doubt that a large number of reliable and complete information sources are needed for every listed enterprise and its industry to carry out comprehensive and systematic investigation and analysis in order to achieve accurate and objective evaluation of the value of the company to be listed. And using professional expertise to conduct rigorous and objective research, which clearly only institutional investors can do, we also call informed investors.

However, there are a large number of small and mediumsized investors in the market, especially in China's A-share market. They have only a small number of open or lagging sources of information, and they lack the ability to analyze and investigate objectively and professionally. So we also call it an uninformed investor. Although many literatures have considered small and medium-sized investors when studying the mechanism of IPO, most of them only put them in a supporting position, such as Benveniste and Wilhelm (1990), Biaisi Bossaertsi and Rochet (2002), etc. Only a few scholars focus on the effect of uninformed investors on the bidding behavior of institutional investors in the IPO market and on the issuer's income, such as Maksimovic and Pichler (2006), which may be related to the maturity of foreign markets and the institutional orientation of investors. Chinese scholars Gong Rukai, Yao Dongmin and Yang Jijun have done some research and progress on the optimal IPO mechanism.

However, in China's A-share market, due to the lack of investor education, the weak investment concept, the longterm speculative atmosphere, and the imperfect market institutional environment etc, a very large number of small and medium-sized investors have been created. Their irrational trading behavior exacerbates the irrational performance of the secondary market, which tends to go up and down too much, while in the primary market, There is no doubt that their behavior will also have an important impact on institutional investors' bidding behavior, issuer's pricing strategy and issuance income. If the enthusiasm of small and medium-sized investors for new shares is high, then for institutional investors, they will try their best to raise their quotations at the initial inquiry stage in order to ensure that they can obtain the second stage cumulative inquiry qualification. And offer high prices at the cumulative inquiry stage in the hope of getting more effective requisition shares, because the hot primary market often means a crazy secondary market, that is, high under-pricing and high returns; for issuers, as a seller of new shares, The more intense buyer competition caused by the active participation of small and medium investors will undoubtedly benefit them to raise the issue price and obtain more issuance 
income. Based on this consideration and the fact that there are a large number of small and medium investors in the A share market, this paper intends to examine the pricing mechanism of new stock issuance from the perspective of small and medium investors.

In this paper, under the framework of asymmetric information and auction price mechanism, according to the principle of mechanism design, we study the IPO market. The impact of the participation of small and medium-sized investors as uninformed investors on the bidding behavior of institutional investors and on the pricing and issuing income of issuers, it also discusses the information disclosure strategy and influence of the underwriters who have mastered the participation of small and medium investors in quantitative information.

\section{LITERATURE REVIEWED}

The research on IPO pricing mechanism from the micro level mainly focuses on the efficiency comparison and analysis among auction, fixed price and cumulative inquiry, for example, from the under-pricing of IPO (the difference between the issue price and the price difference after the listing of the stock), the issue cost, after listing price performance and other aspects of research. Scholars who study IPO mechanism hope to analyze the basic principle of different IPO pricing mechanism theoretically or explain the basic mechanism of IPO pricing mechanism from empirical evidence. This paper will pay more attention to the research progress in theory.

Next, this paper will make a detailed review of the research progress and current situation of IPO pricing mechanism at home and abroad, and further clarify the origin of this study and its relationship with the existing literature conclusions.

Up to now, the theoretical research on IPO pricing mechanism is relatively few, mainly focusing on the pricing efficiency, that is, under-pricing. Only a few scholars study the IPO mechanism design from the perspective of mechanism design.

In the research of IPO under-pricing, Yang Jijun (2006) expanded the model of Biais and Faugerson-Crouz (2002). The study found that because the fixed price pricing mechanism cannot fully and truly reflect investors' information about new shares, its under-pricing rate is often higher than the two pricing mechanisms of unified price auction and cumulative bidding pricing. It is found that the under-pricing level among the three pricing mechanisms will tend to be the same only if all the information privately owned by investors is a bad signal. At the same time, the difference between unified price auction and accumulative bidding mechanism is mainly determined by investors' rational restraint behavior.

Zhou Xiaohua et al. (2009) gave the concept of net under-pricing of new shares. Based on the analysis and research idea of public goods auction with the same price, under the assumption of homogeneous institutional investors and neutral risk attitude, with the aim of maximizing the expected utility of institutional investors, this paper studies institutional investors. The best quoted price strategy under the premise of fixed total amount of new shares applied for before initial public offering, and the exact form of IPO price and IPO net under-pricing when the market is in equilibrium. They deduced that the linear bidding strategy should be strictly superior to the nonlinear bidding strategy, at the same time, the degree of institutional investors' masking demand is positively related to the net under-pricing of the new issue and the net under-pricing must exist. In addition, Zhou Xiaohua and Zhang Jian (2007) analyzed the IPO strategy and IPO under-pricing of the listed companies in the initial public offering stage with the help of the optimal auction principle. Using the "display principle" to construct the institutional investors in the initial public offering process, the expected income model of small and medium-sized investors and listed companies is analyzed and solved under the condition that the expected issuance income of the proposed listed companies is maximized and the real reporting information of institutional investors is guaranteed. Then the equilibrium price is deduced on the basis of the game between the interests of the listed company, the middle and small investors and the institutional investor, and the reason of the formation of IPO under-pricing is obtained. In the end, we choose all the new stocks listed in China's stock market in 2004, and take the profit per share and the net asset per share as the two indicators to measure the intrinsic value of the new shares, and make an empirical test to the above conclusions.

At present, domestic scholars use mechanism design principle to study IPO mechanism from the assumption that institutional investors are homogeneous. For example, Gong Rukai and Yao Dongmin (2012) take China's unique new issue mechanism as the analysis background and study the optimal IPO mechanism based on the mechanism design principle. They describe the current pricing process of IPO in China. And compared with the accumulative bidding inquiry system adopted in the mature stock market of other countries, the basic characteristics of the IPO pricing mechanism in China are summarized, and the theoretical support and decision-making basis for the reform of the new issue system are expected to be promoted in our country.

From the point of view of information structure, Rock (1986) thinks that investors are asymmetric to each other in the theoretical research of IPO issuance mechanism abroad, mainly from the point of view of Rock (1986). And the investors are divided into informed investors and uninformed investors according to the amount of information they have and the accuracy of the information. The winner-curse hypothesis is put forward. The hypothesis suggests that only if an unsuspecting investor thinks that the IPO price can be reduced enough to make up for the possible losses he may suffer from participating in a new share purchase, to ensure that unsuspecting investors do not leave the primary market. Rock believes that the existence of IPO under-pricing is due to adverse selection problems, which means that the degree of under-pricing will increase as uninformed investors become more uncertain about IPO's value. 


\section{MODEL ANALYSIS}

In this paper, there are four kinds of market participants in IPO environment: issuer, underwriter, informed investor and uninformed investor. The issuer and the underwriter have the same demand in the pursuit of maximum issue income. The proposed listed company plans to issue a fixed number of shares, without losing its generality, assuming that the number is 1 . The market valuation $v$ of new shares is from a certain distribution in a bounded range $[\underline{v}, \bar{v}]$. There is $N$ informed investor in the market who knows the true value. The amount of money each unsuspecting investor has is $m$, without loss of generality, hypothetical $m=1$. The number of unsuspecting investors participating in the new share purchase is $\theta$ : assuming $\theta$ a certain distribution from above $[\underline{\theta}, \bar{\theta}]$, the whole unsuspecting investor can buy all the new shares without budget constraints, $\underline{\theta} \phi \bar{v}$. that is, everyone is risk-neutral.

In addition, we simplify some conditions and mechanisms, assuming that there are two institutional investors whose valuation $v_{i}, i=1,2$ of the issuer is distributed $U[0,1]$ and independent; if the market values the issuer $v=\frac{v_{1}+v_{2}}{2}$, the issuer's expected income $E(R)$ cannot exceed $E(v)$, otherwise, informed investors will not be able to obtain information rent, the issuer will not be able to obtain information.

The issuer announces a issue pricing scheme $p\left(q_{i}\right)$ in advance, that is, if the investor is informed of the purchase of the $q_{i}$ stock, the issuer will pay $p\left(q_{i}\right)$ to the issuer; the informed investor determines the quantity ${ }^{q_{i}}$ of the purchase according to the personal valuation information he has mastered, and confirms the payment $p\left(q_{i}\right)$ to maximize the income; finally, the remaining $1-q_{1}-q_{2}$ shares are allocated to the small and medium investors to ensure their participation and constraints, price $p_{s}=E\left(\frac{v_{1}+v_{2}}{2}\right)=\frac{1}{2}$.

This section simplifies consideration and omits the decision process for issuer pricing scheme $p\left(q_{i}\right)$, suppose $p\left(q_{i}\right)=q_{i}^{\alpha}, 0<\alpha<1$. Informed investors 1 choose $q_{1}$, maximize expected income

$$
\begin{aligned}
& E\left[q_{1}\left(v-q_{1}^{\alpha}\right)\right]=E\left[q_{1}\left(\frac{v_{1}+v_{2}}{2}-q_{1}^{\alpha}\right)\right] \\
& =\frac{v_{1} q_{1}}{2}-q_{1}^{\alpha+1}+\frac{q_{1} E V_{2}}{2}=\frac{v_{1} q_{1}}{2}-q_{1}^{\alpha+1}+\frac{q_{1}}{4}
\end{aligned}
$$

According to the first order condition $\frac{v_{1}}{2}-(\alpha+1) q_{1}{ }^{\alpha}+\frac{1}{4}=0$ and the second order condition $-\alpha(\alpha+1) q_{1}^{\alpha-1}<0 \quad$, get $q_{1}^{*}=\left[\frac{2 v_{1}+1}{4(1+\alpha)}\right]^{\frac{1}{\alpha}}$ as the maximum

point; in a similar manner, $q_{2}{ }^{*}=\left[\frac{2 v_{2}+1}{4(1+\alpha)}\right]^{\frac{1}{\alpha}}$ maximizes the expected return on investors 2 .

Suppose the issuer has the right to sell, so as to allocate the following: if $q_{1}{ }^{*}+q_{2}{ }^{*}<1$, the two informed investors obtained $q_{1}{ }^{*}, q_{2}{ }^{*}$ shares, retail investors gain $1-q_{1}-q_{2}^{*}$ share; the income of the issuer is $q_{1}^{* \alpha+1}+q_{2}{ }^{* \alpha+1}+\frac{1}{2}\left(1-q_{1}{ }^{*}-q_{2}{ }^{*}\right)$. If $q_{1}{ }^{*}+q_{2}{ }^{*} \geq 1$, the informed investor shall place the shares on a proportional basis and obtain the respective $\frac{q_{1}{ }^{*}}{q_{1}^{*}+q_{2}{ }^{*}}, \frac{q_{2}{ }^{*}}{q_{1}{ }^{*}+q_{2}{ }^{*}}$ share, undistributed by retail investors, issuer's income is $\frac{q_{1}^{* \alpha+1}+q_{2}{ }^{* \alpha+1}}{q_{1}^{*}+q_{2}^{*}}$.

The above analysis is based on the auction model, and among them, informed investors choose the optimal amount of new shares according to the real $v_{i}$, and pay the corresponding price. The results are consistent with our economic intuition, because more investors buy, more competitive they are, and more favorable it is for issuers as sellers to raise pricing and revenue.

\section{CONCLUSION}

In this paper, the number of unsuspecting investors participating in the new share purchase, that is, the number of small and medium-sized investors, plays a key role, according to the assumption that the exact value is in the hands of the underwriters. The underwriters, as intermediaries linking the issuer and the investor, always default to report the true value truthfully, based on the following considerations:

According to model analysis, the larger the $\theta$ value, the smaller the number of shares the issuer allocates to investors reporting low valuations, thereby allowing more shares to be used to motivate high-value investors. But the high valuation investor also obviously can bear the relatively high price, therefore from the issuer's angle, the greater the $\theta_{\text {value, is }}$ more advantageous to its raises the price, increases the issuance income. The underwriters usually collect a certain proportion of the income as underwriting fees, so if only one issue is considered, as a game, the underwriter also has the power to exaggerate $\theta$.

So in reality, because of the continuous occurrence of new stock listing, the underwriters and investors are two sides of an infinite repeated game. The investors can know the real $\theta$ value after each issue, once the investors find the underwriters, $\theta$ value are false, it is inevitable to adjust the 
requisition strategy next time, or no longer participate in the underwriting of the underwriting new issue, which makes the underwriter face the double loss of reputation and economy.

Under the framework of asymmetric information and uniform pricing rules, this paper designs an optimal pricing mechanism for new issues from the perspective of issuers, which enables informed investors to disclose the valuation information they have and maximize the revenue of issuers.

At the same time, this paper highlights the impact of small investors' participation on the design of optimal IPO mechanism in unified pricing, that is, the impact of informed investors on the number of shares and information rents allocated, as well as the impact on the issuer's distribution and payment strategy and distribution revenue. We concluded that more small and medium-sized investors to participate in the purchase, more conducive to issuers to raise the issue pricing, and increase the issue income.

As an immature market, China's stock market has a weak investment philosophy, a strong speculative atmosphere, and a very large number of small and medium-sized investors, although small and medium-sized investors are not the object of inquiry. However, their purchase and purchase behavior will undoubtedly have an important impact on the pricing strategy of the listed company and the final issue income; since the A-share market in China is a market with Chinese characteristics, including the IPO pricing system and so on, there are many shortcomings and drawbacks, even it is considered to be an important reason for the stock market to deviate from the high economic growth for a long time. The pricing system of the new issue has been revised many times, and the new issue has been suspended and restarted many times. In summary, the immature market environment and the flawed pricing mechanism for new stock issuance mean that a market-oriented, legalized and effective pricing mechanism for new share issuance that is suitable for China's national conditions and can effectively protect the interests of investors, which also needs constant theoretical and practical exploration.

\section{REFERENCES}

[1] Benveniste, L. M., and P. A. Spindt. How Investment Bankers Determine the Offer Price and Allocation of New Shares[J]. Journal of Financial Economics, 1989, 24: 343-361.

[2] Stoughton, N. M., and J. Zechner. IPO-Mechanisms, Monitoring and Ownership Structure[J]. Journal of Financial Economics, 1998,49: 45-77.

[3] Bennouri, M., and S. Falconieri. The Optimality of Uniform Pricing in POs: An Optimal Auction Approach[J]. Review of Finance, 2008, 12: $673-700$.

[4] Benveniste, L. M., and W. J. Wilhelm. A Comparative Analysis of IPO Proceeds Under Alternative Regulatory Environments[J].Journal of Financial Economics, 1990, 28: 173-207.

[5] Biais, B., P. Bossaerts, and J.C. Rochet. An Optimal IPO Mechanism [J]. Review of Economic Studies, 2002, 69: 117-146.

[6] Malakhov, A. The Role of Uninformed Buyers in Optimal IPO Mechanisms, or what Google Did Right and Facebook Did Wrong [J].unpublished working paper, University of Arkansas, 2012.

[7] Gong Rukai, Yao Dongmin. Optimal IPO Mechanism Design: theory and practice in China [J]. Southern economy, 2012, 12: 3-17
[8] Yang Jijun, Zhao Changwen, yang Dan. Research Progress of IPO Distribution Mechanism: a Review [J]. Accounting study 2008,11:76-83. 